\title{
Sex differences in verbal aggression use in romantic relationships: a meta-analytic study and review
}

\author{
Laura Stockdale \\ Loyola University Chicago \\ Sarah Tackett \\ Brigham Young University - Provo \\ Sarah M. Coyne \\ Brigham Young University - Provo, smcoyne@byu.edu
}

Follow this and additional works at: https://scholarsarchive.byu.edu/facpub

Part of the Other Social and Behavioral Sciences Commons

\section{Original Publication Citation}

Stockdale, L. A., *Tackett, S. L., \& Coyne, S. M. (2013). Sex-differences in verbal aggression use in romantic relationships: A meta-analytic study and review. Journal of Aggression, Conflict, and Peace Research, 5, 168-178.

\section{BYU ScholarsArchive Citation}

Stockdale, Laura; Tackett, Sarah; and Coyne, Sarah M., "Sex differences in verbal aggression use in romantic relationships: a meta-analytic study and review" (2013). Faculty Publications. 4027. https://scholarsarchive.byu.edu/facpub/4027 


\title{
Sex differences in verbal aggression use in romantic relationships: a meta-analytic study and review
}

\author{
Laura Stockdale, Sarah Tackett and Sarah M. Coyne
}

\author{
Laura Stockdale is a $\mathrm{PhD}$ \\ candidate at Loyola \\ University Chicago, Chicago, \\ Illinois, USA. \\ Sarah Tackett is based at \\ Brigham Young University, \\ Provo, Utah, USA. \\ Sarah M. Coyne is an Assistant \\ Professor at Brigham Young \\ University, Provo, Utah, USA.
}

\begin{abstract}
Purpose - The current study aimed to investigate potential sex differences in the use of verbal aggression in romantic relationships.

Design/methodology/approach - The current study used meta-analytic methodology to analyze 20 studies to understand gender differences in the use of verbal aggression in romantic relationships.

Findings - The results found that women used more verbal aggression than men in romantic relationships; however, overall levels of verbal aggression use were relatively high regardless of sex.

Research imitations/implications - Limitations of the current research, such as calling for less exploratory research and the need for theories grounded in human coupling research, and suggestions for future research are provided.

Practical implications - Advice for clinicians and practitioners regarding verbal aggression in romantic relationships is discussed with particular emphasis on the possibility of including measures against verbal aggression in interventions on positive couple communication.

Originality/value - The current study adds to the literature by addressing which sex uses more verbal aggression in romantic relationships and providing a critical review of the existing literature with recommendations and limitations of the field.
\end{abstract}

Keywords Aggression, Verbal aggression, Conflict, Couples, Conflict resolution, Gender

Paper type Research paper

Verbal aggression or the verbal behavior intended to damage the self-concept of another (Weber and Patterson, 1997), such as yelling, screaming, insulting, or putting down (MuñozRivas et al., 2007), is a relatively common form of aggression. For example, young children (Tapper and Boulton, 2004), adolescents (White and Humphrey, 1994), and adults (Campbell et al., 1997) use verbal aggression in their peer and romantic relationships. While researchers have begun to examine the developmental correlates of verbal aggression use and victimization such as family (Olsen et al., 2010; Palazzolo et al., 2010), community (Kupersmidt et al., 2000), and peer influences (Salmivalli et al., 2000), other researchers have focussed on the consequences to individuals and relationships as a result of verbal aggression. Researchers have found an association between being a victim of verbal aggression and increased depression (O'Donnell et al., 2006), externalizing behaviors (Muñoz-Rivas et al., 2007), and alcohol abuse (Keiley et al., 2009). Similarly, the use of verbal aggression within peer networks is associated with decreased feelings of warmth (Murray-Close et al., 2007), closeness (Champion et al., 2003), and friendships (Murray-Close et al., 2007). However, other researchers have argued that more empirical work is needed regarding the use of verbal aggression in romantic relationships (Fair and Vanyur, 2011).

Empirical work regarding the frequency of verbal aggression in romantic relationships is mixed, with studies claiming as many as 90 percent of couples use verbal aggression within their 
romantic relationships (Muñoz-Rivas et al., 2007). Some researchers have argued that verbal aggression in romantic relationships is inherently negative because it is associated with lower relationship satisfaction and quality (Van Dulmen et al., 2012), increased overall conflict (White and Humphrey, 1994), and increased internalizing symptoms (Chung et al., 2011; Keiley et al., 2009). Similarly, verbal aggression in romantic relationships is correlated with physical aggression and abuse (Schumacher and Leonard, 2005) and may be a precursor to physical abuse in romantic relationships (O'Leary et al., 1994). In particular, character attacks, a type of verbal aggression, have been associated with physical abuse in marital relationships (Infante et al., 1990). However, other researchers have argued that verbal aggression in romantic relationships may not be as negative as once believed (Sabourin et al., 1993) and may be a normative experience for couples in romantic relationships (Milardo, 1998).

Researchers have argued that there is great variability in the use of aggression in romantic relationships and thus variability in the outcomes (Strets, 1990). For example, common couple violence (CCV) is more common in romantic relationships, is milder than other forms of aggression, less frequent, and is less likely to escalate to sever physical violence (Johnson, 1995). While no known research has explicitly examined verbal aggression as a form of CCV some research suggests that verbal aggression is not necessarily associated with physical aggression or abuse (Frye and Karney, 2006), suggesting heterogeneity in the pathways to physical aggression in romantic relationships similar to CCV. Likewise, other researchers have argued that verbal aggression use is highly dependent on context, with couples under higher amounts of stress using more verbal aggression with their partners (Bodenmann et al., 2010) and that verbal aggression may be more of a state in romantic couples as opposed to a trait (Sabourin et al., 1993). Finally, with the frequency of verbal aggression use in romantic relationships, researchers have argued that some forms of aggression may be a normative experience for romantic couples, with little impact on their relationship satisfaction or feelings of self-concept, more closely resembling CCV than physical abuse (Henning et al., 2006).

However, other researchers have argued that regardless of the variability in the trajectories from verbal aggression to physical aggression, that verbal aggression is a form of intimate partner violence (Fair and Vanyur, 2011) and warrants more research attention. In fact, James and MacKinnon (2010) identified lack of clarity regarding frequency and perpetration of non-physical forms of abuse as one of the most serious problems facing clinicians today. Clearly, more research is needed regarding the impact of verbal aggression in romantic relationships on relationship outcomes and abuse. Verbal aggression may not be associated with marital stability, but researchers argue that it is consistently associated with decreased relationship satisfaction (Bodenmann et al., 2010). In fact, the early years of marriage seem to be particularly important to understanding the relationship between verbal aggression use in romantic relationships and relationship satisfaction, stability, self-esteem, and trajectories to physical aggression (Schumacher and Leonard, 2005). While the research regarding the impact of verbal aggression in romantic relationships is conflicting, it is also important to understand sex effects on the perpetration of aggression in romantic relationships.

\section{Sex difference in perpetration of aggression in romantic relationships}

Research regarding the impact of sex on perpetration of aggression in romantic relationships is inconsistent, with some researchers arguing that there are significant sex differences in aggression in romantic relationships (Linder et al., 2007) and others arguing few significant sex differences (Bagner et al., 2010). For example, Graham-Kevan and Archer (2009) found that men and women in romantic relationships overall use similar levels of control in their relationships, however, the methods of control were markedly different in both sexes. Likewise, other researchers have argued that as the type of aggression escalates, sex differences become more pronounced (Archer, 2004), with men using more physical aggression in romantic relationships than women (Archer, 2004), and women using more relational aggression and psychological control (Murray-Close et al., 2010). However, other researchers have argued that women and men display no significant differences in their use of physical (Linder and Collins, 2005) and relational aggression (Bagner et al., 2010) in romantic relationships.

PAGE 168 | JOURNAL OF AGGRESSION, CONFLICT AND PEACE RESEARCH | VOL. 5 NO. 32013 
The sex differences regarding verbal aggression perpetration in romantic relationships are equally mixed. Some researchers have argued that outside of the context of romantic relationships, women use more verbal aggression toward their peers than men (Archer et al., 1988). However, other researchers have argued that there are no significant differences between men and women in their use of verbal aggression with their peers (Tapper and Boulton, 2004). Likewise, in the context of romantic relationships, some researchers have argued that women use more verbal aggression than men (Muñoz-Rivas et al., 2007), while others argued no significant sex differences in verbal aggression perpetration in romantic relationships (Sabourin et al., 1993). This lack of consistency may be due to the reciprocal nature of verbal aggression in romantic relationships (Sabourin et al., 1993). In contrast, researchers have also postulated that verbal aggression may only be reciprocal when first initiated by females (Schumacher and Leonard, 2005). Clearly, more research is needed regarding the frequency of verbal aggression in romantic relationships and the potential impact of sex on the perpetration of verbal aggression in romantic relationships. Given the conflicting literature surrounding the impact of verbal aggression in romantic relationships on relationship and mental health outcomes and the potential trajectories towards escalating aggression, it is important to understand the frequency of verbal aggression in romantic relationships and if there are sex differences in the amount of verbal aggression use in romantic relationships.

\section{Theoretical approach}

According to Social Role Theory (SRT) differences in appropriate behavior based on sexuality are a result of the traditional division of labor historically seen between men and women (Eagly, 1987). This division of roles led to the socialization of sex specific appropriate behaviors and the creation of more "gendered" characteristics (Eagly et al., 2000). These roles generally include instrumental traits for males and expressive or communicative traits for females. For example, gendered personality traits usually consists of feminine traits (e.g. compassionate, tender), masculine traits (e.g. self-reliant, analytical), and neutral personality traits (e.g. friendly, sincere) (Gaunt, 2006). While typically this theory has been used to show the traits associated with male aggression (Archer, 2004), others have argued that this view is too simplistic and lacking key evolutionary components associated with aggression.

For example, Archer (2009) argued that while SRT may explain aggression within the same sex, it does not adequately account for aggression between opposite sexes or for the increasingly androgynous society in which western men and women now mate. In contrast to the SRT of aggression the sexual selection (Darwin, 1871) theory argues that the innate drive to reproduce causes competition within males and increased choices within women. According to this theory, there is an inherit conflict of interest between men and women regarding the costs and benefits of reproduction. This conflict of interest and imbalance of power has shifted in western societies with the sexual revolution; however, discrepancies still exist within sexes regarding reproduction and power. Therefore, these power imbalances and innate drive to reproduce causes sex differences in the display of aggression in romantic relationships. While this theory has traditionally been used to understand gender differences in physical aggression, it is particularly suited to understanding female aggression in romantic relationships because it takes into account the evolutionary drive to mate and the changing power dynamics in romantic relationships.

\section{Research rationale}

Meta-analysis is a systematic tool for reviewing a body of research by integrating findings from all quantitative studies on a given topic. Studies are coded on key variables and results are standardized to allow for meaningful comparison (Lipsey and Wilson, 2001). The existing literature on verbal aggression in intimate relationships is broad and often conflicting regarding the impact of sex on verbal aggression use. However, there are currently no meta-analytic studies specifically examining use of verbal aggression in romantic relationships based on sex. We focussed this meta-analysis on studies of verbal aggression in intimate relationships that report on both men and women because of the lack of clarity and consistency regarding sex 
differences in the use of verbal aggression in romantic relationships and the potential implications of verbal aggression use on relationship outcomes and relationship trajectories. Drawing upon our findings, we discuss implications for research to guide future efforts in practice and evaluation with regards to verbal aggression in romantic relationships. Therefore the following research questions will guide the paper: are there significant differences in the use of verbal aggression in romantic relationships? and do other variables influence the relationship between sex and the use of verbal aggression?

\section{Method \\ Search procedure}

We examined all databases that are likely to contain peer-reviewed papers that have data on verbal aggression. Specifically, papers must focus on the use of verbal aggression within intimate relationships (romantic, marriage, dating, etc.). Initially, this involved Ingenta, Psychlnfo, Sciencedirect, and Web of Science. However, verbal aggression is given several names in the research literature. Many peer-reviewed articles also included measures of domestic violence (e.g. partner violence, partner aggression, relationship aggression, etc.) within their studies on verbal aggression. Given the broad terminology we initially used the following broad terms in our search: controlling behaviors (behaviors), dominance, emotional abuse, emotional aggression, emotional violence, psychological abuse, psychological aggression, psychological violence, verbal abuse, verbal aggression, verbal violence, romantic relational aggression, relational aggression, indirect aggression, and social aggression. These searches returned 516 research reports. From this list we identified 91 primary research reports of controlling behavior related to verbal aggression for closer examination, based on abstracts and titles alone. From these identified studies reference lists and reviews of literature were also searched. Relevant studies were found and attended to the study when appropriate. Past meta-analyses on aggression in romantic relationships were also examined for relevant studies.

\section{Inclusion criteria}

This initial search criteria left over 91 studies for further examination. Below is a description of further selection and inclusion criteria that were employed for the current study.

Types of aggression. Due to the extensive research that has been conducted thus far on the topic of aggressive behaviors in couple relationships, we chose to include only studies that specifically evaluated reports on verbal aggression, separate from other types of aggression, such as controlling and power assertion, generalized abuse, relational aggression, and physical abuse. Therefore, eligibility was based upon reports of verbal aggression within the context of a romantic/intimate relationship. Many studies combined verbal aggression and psychological abuse or control. However, because of the developmental trajectory that separates these forms of aggression and the fact that verbal aggression is not inherently controlling, we felt that such terms should not be combined. Therefore, studies that combined these terminologies were excluded from the current analysis. Furthermore, while verbal aggression and psychological control and abuse are similar, there is an inherent distinction between the two terms based off of severity and the underlying motivation behind each behavior. Psychological abuse implies the intent to manipulate or control another, while verbal aggression does not require this underlying intent. Verbal aggression, by established definition, only requires the intent to harm.

Relationship status and gender reports. All studies included analyses on sex differences on verbal aggression in their intimate couple relationship (e.g. dating, married, or separated/ divorced). Consequently, we limited this meta-analysis to studies that only included reports from both men and women, independently, in romantic couple relationships, and eliminated those providing reports from only one gender, and/or those focussed on other relationships (e.g. sibling, parent-child relationships). For example, for a study to be included in this meta-analysis both men and women had to report on either their own or their partners verbal aggression in their romantic relationships. Studies were only women reported on their own or their partners verbal aggression were excluded as were studies were only men reported on their own or their partners verbal aggression. This allowed for a direct test of sex differences in verbal aggression. We also

PAGE 170 | JOURNAL OF AGGRESSION, CONFLICT AND PEACE RESEARCH | VOL. 5 NO. 32013 
did not use one study that focussed on reports from individuals in homosexual/bisexual relationships (Kelley and Robertson, 2008). One study reported comparisons between gay and lesbian relationships, and included reports about both males and females (Thomas and Richard, 2008). However, while this information would have been interesting and both sexes were reported, the individuals within this study were not in heterosexual relationships. Therefore, there could be fundamental differences between the use of verbal aggression in heterosexual and homosexual relationship and associations between verbal aggression and other forms of aggression. For these reasons we did not feel it was appropriate to include this study in our final analyses; nevertheless, future research should continue to address homosexual couples and verbal aggression.

Publication status. We included both published and unpublished works to directly examine publication bias. We searched for doctoral dissertations and master's theses, as well as journal articles, books, and book chapters.

Other. We could not use four reports where the study did not distinguish between the sex of participants or where the sex of participants were ambiguous (e.g. referring to individuals' in romantic relationships as partner one and partner two). Additionally, two reports lacked sufficient statistical information to compute an effect size, and three reports were not available in English. This resulted in a final sample of 20 studies for our meta-analysis.

\section{Variable coding}

The codebook consisted of 14 items to systematically code moderators relevant to the subject of verbal aggression in intimate couple relationships (a copy of the codebook is available upon request). Moderators of the study were relationship status (e.g. dating or married) and report source (e.g. peer-reviewed article, thesis, dissertation).

Five trained coders examined the studies. Each coder evaluated studies based on the inclusion criteria (noted above) as well as outcome variables and moderators. After separately coding, the coders compared answers. The initial coding scores before discussion yielded acceptable interrater reliability $(K=0.75)$. When rare coding discrepancies occurred, coders discussed their rationale and sought further clarification from the study text until they reached agreement. In cases where the coders were unable to come to a consensus, the coders discussed the differences with the other authors until a consensus was reached. In this coding procedure, which emphasizes agreement on objective information, the interrater reliability becomes perfect.

\section{Computing and reporting of effect sizes}

Effect sizes were computed with Comprehensive Meta Analysis (CMA) II (Biostat, 2006). Standardized mean group differences were calculated for men and women with assumed independence, meaning the standardized mean change score was computed for two independent group studies with one being men and the other being women. This independence approach was most appropriate because the studies did not specify that the men and women in their studies were engaged in romantic relationships with each other. Therefore, it is appropriate to assume that participants in each study were independent of one another and therefore levels of verbal aggression should be independent. Each effect size was weighted by the squared standard error to account for the precision of the effect size estimate (Lipsey and Wilson, 2001). The studies included in the sample had diverse and occasionally small sample sizes, therefore a Hedges' (1981) correction to reduce small sample biases was used. We reported the random effects results because meta-analytic experts now recommend the report of these effects as standard practice because they allow for the possibility that differences in effect sizes from study to study are not only associated with participant-level sampling error, but also with variation in study methods (Shadish and Baldwin, 2003).

For this meta-analysis, we used means and standard deviations for computing effect sizes. In the cases where means and standard deviations were not provided in the studies included, we coded for other statistics. All possible statistics were used within this meta-analysis. In our final analyses, we used means, standard deviations, $\chi^{2}$, proportions, and frequencies. 
In meta-analysis, $d$ expresses the magnitude of the effect size comparing one group to another; $k$ expresses the number of coded studies that contribute to the overall effect size; $Q$ tests the statistical difference between groups and is analogous to the more common $t$ statistic (Lipsey and Wilson, 2001).

\section{Summary of participants and studies included}

Of the 20 studies that were coded, over half were from a US population and the majority of these were white, middle-class individuals. Only one study included primarily low-income samples and this was a study specifically examining Palestinians. While there was a substantial amount of representation from other countries, the majority of these countries still reported on the dominant culture of their country (e.g. Israel reported on Jewish individuals).

Additionally, the vast majority of our studies examined emerging adults and college students (17 studies), while a few examined older adults. With that, the majority reported on dating and cohabiting couples; few reported on married couple relationships. Three of the studies used married couples only, 14 of the studies used dating couples, and the remaining studies examined a mix of both dating and married couples.

Typically, verbal aggression in romantic relationships was reported in a self-report, Likert scale. The majority of studies used this approach to study verbal aggression in romantic relationships and the vast majority used behaviorally based scales that asked about an individuals' behavior on a daily, weekly, or monthly basis. Reports were obtained for both men and women in romantic relationships and few studies contained partner ratings of verbal aggression.

Results

Overall effects of gender on verbal aggression

When we examined verbal aggression in regards to gender, we found an overall significant effect $(d=-0.25, p<0.001, k=20)$ indicating that women initiated more verbal aggression than men. To further investigate the relationship between verbal aggression and gender, we separated studies that reported high levels of verbal aggression versus low levels of verbal aggression. High levels of verbal aggression were defined as occurring multiple times within a given week, while low levels of verbal aggression were defined as happening rarely or infrequently. There was no significant difference between high and low levels of verbal aggression perpetration $(Q(20)=6.23, p>0.05)$ with women initiating both high $(d=-0.26)$ and low $(d=-0.23)$ levels of verbal aggression more frequently.

\section{Moderators of the overall effect size}

There is a substantial systematic heterogeneity in the distribution of effect sizes, $Q(19)=78.37$, $p<0.001$. This suggests that moderators may be influential in the variability on the effect of gender on verbal aggression. Although we coded for several methodological moderators and were prepared to analyze these, the small number of studies in our analyses constrained our ability to accurately analyze the moderators. There was also a substantial lack of variability within our sample, which significantly limited accurate analyses of moderators. However, we were able to evaluate some methodological and sample moderators and discuss these moderators in detail below. Due to the limitations of CMA II, we could not evaluate within gender groups to understand why women may be initiating more verbal aggression than men. However, looking at the differences between genders, we discuss the moderators in contextual and practical terms.

Relationship status. We also anticipated that relationship status would be a significant moderator of verbal aggression perpetration between genders with significant differences being observed between dating, cohabiting, or married couples. However, no such difference was found within the sample $(Q(6)=34.94, p>0.05)$. Effect sizes differed between studies examining dating couples and those evaluating married and cohabiting couples $(d=-0.18$, $k=14, p>0.05 ; d=-0.42, k=3, p>0.05$, respectively).

Report source. It was additionally anticipated that the type of report source (self or partner) would be a significant moderator of the study. However, there was no significant difference

PAGE 172 | JOURNAL OF AGGRESSION, CONFLICT AND PEACE RESEARCH | VOL. 5 NO. 32013 
between self-report $(d=-0.22, k=14, p>0.05)$ vs partner-report $(d=-0.12, k=6, p>0.05)$ assessments of verbal aggression perpetration $(Q(4)=0.32, p>0.05)$.

\section{Review of the literature in the meta-analysis}

Meta-analytic studies provide a unique opportunity to survey a specific body of literature to understand overall effects and moderating variables. However, it also provides an opportunity to critically evaluate the existing literature for strengths and weaknesses. There has been an explosion in the last decade in research examining verbal aggression (Chung et al., 2011) and with this has come increased attention to verbal aggression in romantic relationships. Great strides have been made regarding understanding the frequency of verbal aggression use in romantic relationships among adolescents, emerging adults (White and Humphrey, 1994), and adults (Campbell et al., 1997). Similarly, cross culturally studies have shown that verbal aggression is present across the globe (Muñoz-Rivas et al. , 2007) and an issue facing of couples in romantic relationships from a variety of backgrounds and culture.

The current literature has also made great strides in understanding the relationship between sex and verbal aggression use in romantic relationships. Researchers are increasing reporting on both men and women's use of verbal aggression in romantic relationships and no longer assuming that verbal aggression is strictly a "female" form of aggression. These exploratory studies are vital to the literature and are important for understanding the prevalence and sex differences in verbal aggression use in romantic relationships. While these researchers have significantly contributed to the literature, weaknesses still exist and vital questions have been left unanswered.

The literature in the current meta-analysis consistently stated or implied that verbal aggression is detrimental to romantic relationships and is a risk factor for physical aggression. Indeed the majority of studies in this analysis cited the trajectories from verbal aggression to physical aggression as a critical rationale for their research. However, current research suggests that not all couples who use verbal aggression make the transition to physical aggression (Sabourin et al., 1993) and given the high rates of verbal aggression used by men and women in romantic relationships (Muñoz-Rivas et al., 2007), this assumption may be unfounded. Few researchers, if any, have investigated weather verbal aggression may be a normative part of romantic relationships and if in moderation this may be a normative part of couple communication. Future researchers should further investigate the associations between verbal aggression in romantic relationships, relationship quality, and satisfaction, taking into account diverging trajectories of verbal aggression use. Similarly, cluster analyses could provide a unique opportunity to understanding the role of verbal aggression to relationship qualities and other forms of aggression. Given the high rates of verbal aggression use by men and women in romantic relationships, it seems likely that some healthy, stable, and high-quality romantic relationships will contain verbal aggression.

Researcher regarding couple communication in romantic relationships may shed some light on these seeming discrepancies and may help guide the literature regarding verbal aggression in romantic relationships to a more balanced perspective. Research into couple communication has shown certain behaviors such as criticism, contempt, and emotionally stonewalling place couples at increased risk for relationship dissolution (Gottman and Levenson, 2000). However, research has also shown that couples can frequently have verbal altercations, but as long as they do not attack the character of their partner, have contempt, and emotionally stonewall their partner, they can have healthy and long lasting romantic relationships (Gottman, 1991). These behaviors clearly heavily overlap with verbal aggression, however, this research is rarely cited in the verbal aggression in romantic relationships literature. Future researchers should take into account more cross disciplinary research to help develop a clearer picture of the impact of verbal aggression in romantic relationships.

Finally, the current research regarding verbal aggression in romantic relationships has been primarily exploratory and therefore has been weakly guided by theory. More theories regarding the use of verbal aggression specifically in the context of romantic relationships would greatly aid the field and help place the research findings in a broader relationship context. Future 
researchers should consider developing theories of verbal aggression use grounded in romantic relationship development and maintenance theories. Undoubtedly significant advances have been made in understanding the frequency of verbal aggression in romantic relationships and similarities and differences within the sexes. However, as the field moves beyond exploratory studies, it is important to consider the potential relationship trajectories and theories that may better guide and aid to the understanding of verbal aggression in the broader context of romantic relationships. Grounded in this framework the research will be able to move beyond exploratory studies and begin to investigate the different relational trajectories that include verbal aggression, who is at risk, and where interventions may be necessary and most effective.

\section{General discussion}

The results of the current study suggest that verbal aggression in romantic relationships is relatively common and used by both sexes. While this meta-analysis suggests that women use more verbal aggression in their romantic relationships than men, both sexes were using a significant amount of verbal aggression in their romantic relationships. This increased of verbal aggression by women may simply be due to the fact that women speak more words on average per day than men (Mehl et al., 2007). Perhaps women use more verbal aggression in romantic relationships because they are simply more verbal in general.

Likewise it is still unclear from the research the influence of verbal aggression in romantic relationships on relationship outcomes and other forms of abuse. Some researchers have suggested that verbal aggression in romantic relationships leads to physical aggression and abuse (Schumacher and Leonard, 2005), however, there is great variability in these pathways to physical aggression in romantic relationships and more research is needed before broad statements regarding the relationship between verbal aggression and physical aggression can be made. Similarly, verbal aggression is relatively common in romantic relationships and may just be another form of CCV not associated with negative relationship outcomes and abuse (Frye and Karney, 2006).

While more research is needed to understand the role of romantic verbal aggression in relationship outcomes, the current study adds to the literature by highlighting limitations in the current literature and pointing to the pivotal role of women in understanding the influence of verbal aggression in romantic relationships. Coupling researchers suggest that women are often the gate-keepers of romantic relationships (Allgeier and Royster, 1991; Canary et al., 1997; McCormick and Jesser, 1983) and have argued that to understand the inner workings of romantic relationship women need to be given the opportunity to report and expound on their experiences (Fox and Murry, 2000). Within this framework, it is important that practitioners and clinicians interested in decreasing verbal aggression in romantic relationships spend particular time working with women and understanding the female perspective on why verbal aggression is a communication tool within their relationship.

Similarly, interventions designed to increase and improve positive couple communication may not be adequately addressing the issue of verbal aggression in romantic relationships. Given that researchers have argued that verbal aggression is associated with physical abuse, interventions targeted at less critical couples, such as positive couple communication interventions, may not specifically target verbal aggression. However, these interventions seem an appropriate and timely opportunity to address the influence of verbal aggression on relationship outcomes and decrease verbal aggression in romantic relationships. Clinicians and practitioners should try to incorporate verbal aggression into already existing interventions dealing with couple's positive and negative communication patterns.

While the current study adds to the existing literature it is not without limitations. First, the metaanalysis had relatively few studies and therefore was lacking in power. This lack of power made the examination of moderating variables very difficult. Larger meta-analytic studies should seek to understand potential moderators between sex and verbal aggression use in romantic relationships. Similarly, the current study is correlational and therefore causal relationships cannot be determined. It is unclear if sex really accounts for the finding that women use more

PAGE 174 | JOURNAL OF AGGRESSION, CONFLICT AND PEACE RESEARCH | VOL. 5 NO. 32013 
verbal aggression in romantic relationships or if other variables are confounding this relationship. Future researchers should address these limitations.

Even given the limitations of the current study, this meta-analysis suggests that women use more verbal aggression in romantic relationships than men. It is possible that verbal aggression may lead to more escalated forms of violence and aggression in romantic relationships and may be detrimental to relationship outcomes. Therefore, it is important for researchers, clinicians, and practitioners to seek to understand the female perspective in romantic relationships. Understanding why, when, and how women use verbal aggression with their romantic partners will shed light on outcomes and appropriate sources of interventions to reduce verbal aggression in human coupling.

\section{Implications for practice}

- Verbal aggression in romantic relationships may be relatively common and a form of couple common violence or it may be related to increased aggressive behavior, therefore a critical review of the existing literature is warranted to encourage future researchers to address gaps in the literature.

- Given the frequency of verbal aggression in romantic relationships, therapists and clinicians might be well advised to included measures against verbal aggression in their already existing measures, interventions, and preventions to increase romantic couples positive communication.

- The frequency of verbal aggression in romantic relationships by both sexes that measures to reduce verbal aggression use in romantic relationships need to target both men and women.

\section{References}

(An asterisk * indicates that the reference was used in the meta-analysis).

Allgeier, E.R. and Royster, B.J.T. (1991), "New approaches to dating and sexuality", in Grauerholz, E. and Koralewski, M. (Eds), Sexual Coercion, Lexington Books, Lexington, KY, pp. 133-47.

Archer, J. (2004), "Sex differences in aggression in real-world settings: a meta-analytic review", Review of General Psychology, Vol. 8, pp. 291-322, doi:10.1037/1089-2680.8.4.291.

Archer, J. (2009), "Does sexual selection explain human sex differences in aggression?", Behavioral and Brain Sciences, Vol. 32, pp. 249-311, doi:10.1017/S0140525X09990951.

Archer, J., Pearson, N.A. and Westeman, K.E. (1988), "Aggressive behavior of children aged 6-11: gender differences and their magnitude", British Journal of Social Psychology, Vol. 27, pp. 371-84, doi:10.1111/ j.2044-8309.1988.tb00839.x.

Bagner, D.M., Storch, E.A. and Preston, A.S. (2010), "Romantic relational aggression: what about gender?", Journal of Psychiatric Research, Vol. 44, pp. 393-404, available at: www.journalofpsychiatricresearch.com/

Biostat (2006), Comprehensive Meta-Analysis, Version No. 2.2, Biostat, Englewood, NJ.

*Bodenmann, G., Meuwly, N., Bradbury, T.N., Gmelch, S. and Ledermann, T. (2010), "Stress, anger, and verbal aggression in intimate relationships: moderating effects of individual and dyadic coping", Journal of Social and Personal Relationships, Vol. 27, pp. 408-24, doi:10.1177/0265407510361616.

Campbell, A., Sapochnik, M. and Muncer, S. (1997), "Sex differences in aggression: does social representation mediate form of aggression?", British Journal of Social Psychology, Vol. 36, pp. 161-71, doi:10.111/j.2044-8309.1997.tb01125.x.

Canary, D.J., Emmers-Sommer, T.M. and Faulkner, S. (1997), Sex and Gender Differences in Personal Relationships, Guilford Press, New York, NY.

Champion, K., Vernberg, E. and Shipman, K. (2003), "Nonbullying victims of bullies: aggression, social skills, and friendship characteristics", Journal of Applied Developmental Psychology, Vol. 24, pp. 535-51, doi:10.1016/j.appdev.2003.08.003.

Chung, G.H., Tucker, M.B., Li, G., Zhou, X. and Hwang, S. (2011), "Exploratory analysis of verbal aggression in romantic relationships among unmarried men and women: predictive patters by gender and race", Journal of Social and Personal Relationships, Vol. 28, pp. 1005-23, doi:10.1177/0265407510397984. 
Darwin, C. (1871), The Descent of Man: and Selection in Relation to Sex, Penguin Classics, John Murray, London.

Eagly, A. (1987), Sex Difference in Social Behavior: A Social Role Interpretation, Erlbaum, Hillsdale, NJ.

Eagly, A.H., Wood, W. and Diekman, A.B. (2000), "Social role theory of sex differences and similarities: a current appraisal", in Eckes, T. and Trautner, H.M. (Eds), The Developmental Social Psychology of Gender, Erlbaum, Mahwah, NJ, pp. 123-74.

Fair, C.D. and Vanyur, J. (2011), "Sexual coercion, verbal aggression, and condom use consistency among college students", Journal of American College Health, Vol. 59, pp. 273-80, doi:10.1080/ 074481.2010 .508085 .

Fox, G.L. and Murry, V.M. (2000), "Gender and families: feminist perspectives and family research”, Journal of Marriage and Family, Vol. 62, pp. 1160-72, doi:10.1111/j.1741-3737.2000.01160.x.

Frye, N.E. and Karney, B.R. (2006), "The context of aggressive behavior in marriage: a longitudinal study of newlyweds”, Journal of Family Psychology, Vol. 20, pp. 12-20, doi:10.1037/0893-3200.20.1.12.

Gaunt, R. (2006), "Couple similarity and marital satisfaction: are similar spouses happier?", Journal of Personality, Vol. 74, pp. 1404-20, doi:10.1111/j.1467-6494.2006.00414.x.

Gottman, J.M. (1991), "Predicting the longitudinal course of marriages", Journal of Marital and Family Therapy, Vol. 17, pp. 3-7, doi:10.1111/j.1752-0606.1991.tb00856.x.

Gottman, J.M. and Levenson, R.W. (2000), "The time of divorce: predicting when a couple will divorce over a 14-year period", Journal of Marriage and Family, Vol. 62, pp. 737-45, doi:10.1111/j.1741-3737. 2000.00737.x.

Graham-Kevan, N. and Archer, J. (2009), "Control tactics and partner violence in heterosexual relationships", Evolution and Human Behavior, Vol. 30, pp. 445-52, doi:10.1016/j.evolhumbehav.2009.06.007.

Hedges, L.V. (1981), "Distribution theory for Glass's estimator of effect size and related estimators”, Journal of Educational Statistics, Vol. 6, pp. 107-28, doi:10.3102/1076998600602107.

Henning, K., Renauer, B. and Holdford, R. (2006), "Victim or offender? Heterogeneity among women arrested for intimate partner violence", Journal of Family Violence, Vol. 21, pp. 351-68, doi:10.1007/s10896006-9032-4.

Infante, D.A., Sabourin, T.C., Rudd, J.E. and Shannon, E.A. (1990), "Verbal aggression in violent and nonviolent marital disputes", Communication Quarterly, Vol. 38, pp. 361-71, doi:10.1080/ 01463379009369773.

*James, K. and MacKinnon, L. (2010), "The tip of the iceberg: a framework for identifying non-physical abuse in couple and family relationships", Journal of Feminist Family Therapy: An International Forum, Vol. 22, pp. 112-29, doi:10.1080/08952831003787867.

Johnson, M.P. (1995), "Patriarchal terrorism and common couple violence: two forms of violence against women", Journal of Marriage and Family, Vol. 57, pp. 283-94, doi:10.2307/353683.

Kelley, T.M. and Robertson, R.A. (2008), "Relational aggression and victimization in gay male relationships: the role of internalized homophobia", Aggressive Behavior, Vol. 34, pp. 475-85, doi:10.1002/ab.20264.

*Keiley, M.K., Keller, P.S. and El-Sheikh, M. (2009), "Effects of physical and verbal aggression, depression, and anxiety on drinking behavior of married partners: a prospective and retrospective longitudinal examination", Aggressive Behavior, Vol. 35, 296-312, doi:10.1002/ab.20310.

Kupersmidt, J.B., Bryant, D. and Willoughby, M.T. (2000), "Prevalence of aggressive behaviors among preschoolers in Head Start and community child care programs", Behavioral Disorders, Vol. 26, pp. 42-52, available at: www.ccbd.net/

Linder, J.R. and Collins, W.A. (2005), "Parent and peer predictors of physical aggression and conflict management in romantic relationships in early adulthood", Journal of Family Psychology, Vol. 19, pp. 252-62, doi:10.1037/0893-3200.19.2.252.

Linder, J.R., Crick, N.R. and Collins, W.A. (2007), "Relational aggression and victimization in young adults' romantic relationships: associations with perceptions of parent, peer, and romantic relationship quality", Social Development, Vol. 11, pp. 69-86, doi:10.1111/1467-9507.00187.

Lipsey, M.W. and Wilson, D.B. (2001), Practical Meta-Analysis, Sage, Thousand Oaks, CA. 
McCormick, N.B. and Jesser, C.J. (1983), "The courtship game: power in the sexual encounter", in Allgeier, E.R. and McCormick, N.B. (Eds), Changing Boundaries: Gender Roles and Sexual Behavior, Mayfield Publishing Company, Palo Alto, CA, pp. 64-86.

Mehl, M.R., Vazire, S., Ramírez-Esparza, N., Slatcher, R.B. and Pennebaker, J.W. (2007), "Are women really more talkative than men?", Science, Vol. 317, pp. 82-4, doi:10.1126/science.1139940.

Milardo, R.M. (1998), "Gender asymmetry in common couple violence", Personal Relationships, Vol. 5, pp. 423-38, doi:10.1111/j.1475-6811.1998.tb00180.x.

*Muñoz-Rivas, M.J., Graña, J.L., O’Leary, K.D. and González, M.P. (2007), "Aggression in adolescent dating relationships: prevalence, justification, and health consequences”, Journal of Adolescent Health, Vol. 40, pp. 298-304, doi:10.1016/j.adohealth.2006.11.137.

Murray-Close, D., Ostrov, J.M. and Crick, N.R. (2007), "A short-term longitudinal study of growth of relational aggression during middle childhood: associations with gender, friendship intimacy, and internalizing problems", Development and Psychopathology, Vol. 19, pp. 187-203, doi:10.1017080 954579407070101.

Murray-Close, D., Ostrov, J.M., Nelson, D.A., Crick, N.R. and Coccaro, E.F. (2010), "Proactive, reactive, and romantic relational aggression in adulthood: measurement, predictive validity, gender differences, and association with intermittent explosive disorder", Journal of Psychiatric Research, Vol. 44, pp. 393-400, doi:10.1016/j.jpsychires.2009.09.005.

*O'Donnell, C., Cook, J.M., Thompson, R., Riley, K. and Neria, Y. (2006), "Verbal and physical aggression in World War II former prisoners of war: role of posttraumatic stress disorder and depression", Journal of Traumatic Stress, Vol. 19, pp. 859-66, doi:10.1002/jts.20157.

*O'Leary, K.D., Malone, J. and Tyree, A. (1994), "Physical aggression in early marriage: prerelationship and relationship effects”, Journal of Consulting and Clinical Psychology, Vol. 62, pp. 594-602, doi:10.1037// 0022-006X.62.3.594.

Olsen, J.P., Parra, G.R. and Bennett, S.A. (2010), "Predicting violence in romantic relationships during adolescence and emerging adulthood: a critical review of the mechanisms by which familial and peer influences operate", Clinical Psychology Review, Vol. 30, pp. 411-22, doi:10.1016/j.cpr.2010.02.002.

*Palazzolo, K.E., Roberto, A.J. and Babin, E.A. (2010), "The relationship between parents' verbal aggression and young adult children's intimate partner violence and victimization and perpetration", Health Communication, Vol. 25, pp. 357-64, doi:10.1080/10410231003775180.

*Sabourin, T.C., Infante, D. and Rudd, J. (1993), "Verbal aggression in marriages: a comparison of violent, distressed but nonviolent, and nondistressed couples", Human Communication Research, Vol. 20, pp. 245-67, doi:10.1111/j.1468-2958.1993.tb00323.x.

Salmivalli, C., Kaukiainen, A. and Lagerspetz, K. (2000), "Aggression and sociometric status among peers: do gender and type of aggression matter?", Scandinavian Journal of Psychology, Vol. 41, pp. 17-24, doi:10.1111/1467-9450.00166.

*Schumacher, J.A. and Leonard, K.E. (2005), “Husbands' and wives' marital adjustment, verbal aggression, and physical aggression as longitudinal predictors of physical aggression in early marriage", Journal of Counseling and Clinical Psychology, Vol. 73, pp. 28-37, doi:10.1037/0022-006X.73.1.28.

Shadish, W.R. and Baldwin, S.A. (2003), "Meta-analysis of MFT interventions", Journal of Marital and Family Therapy, Vol. 29, pp. 547-70, doi:10.1111/j.1752-0606.2003.tb01694.x.

Strets, J.E. (1990), "Verbal and physical aggression in marriage”, Journal of Marriage and the Family, Vol. 52, pp. 501-14, available at: www.ncfr.org/jmf

Tapper, K. and Boulton, M.J. (2004), "Sex differences in levels of physical, verbal, and indirect aggression among primary school children and their associations with beliefs about aggression”, Aggressive Behavior, Vol. 30, pp. 123-45, doi:10.1002/ab.20010.

Van Dulmen, M.H.M., Mata, A.D. and Klipfel, K.M. (2012), "Enhancing the assessment of verbal aggression through observational methodology", Journal of Interpersonal Violence, Vol. 27, pp. 812-23, doi:10.1177/ 0886260511423251.

Weber, K. and Patterson, B.R. (1997), "The effects of maternal verbal aggression on the adult child's future romantic relationships”, Communication Research Reports, Vol. 14, pp. 221-30, doi:10.1080/ 08824099709388664. 
White, J.W. and Humphrey, J.A. (1994), "Women's aggression in heterosexual conflicts", Aggressive Behavior, Vol. 20, pp. 195-202, available at: http://onlinelibrary.wiley.com/journal/10.1002/\%28ISSN\% 291098-2337

\section{Further reading}

*Antônio, T. and Hokoda, A. (2009), "Gender variations in dating violence and positive resolution among Mexican adolescents", Violence and Victims, Vol. 24, pp. 533-45, available at: www.springerpub.com/ product/08866708\#.UMzXxnchOWY

${ }^{*}$ Carbonell, O.A. (2010), "Marital conflict, maternal care and preschoolers' attachment security in lowincome, Mexican-American families", Dissertation Abstracts International: Section B: The Sciences and Engineering, Vol. 70, p. 7237.

*Gibb, B.E. and Abela, J.R.Z. (2008), "Emotional abuse, verbal victimization, and the development of children's negative inferential styles and depressive symptoms", Cognitive Therapy and Research, Vol. 32, pp. 161-76, available at: www.springer.com/medicine/journal/10608

*Pradubmook-Sherer, P. (2009), "Prevalence and correlates of adolescent dating violence in Bangkok, Thailand", Journal of Sociology and Social Welfare, Vol. 36, pp. 9-37, available at: www.wmich.edu/hhs/ newsletters_journals/jssw/

*Sherer, P. and Sherer, M. (2008), "Exploring reciprocity in dating violence among Jewish and Arab youth in Israel”, International Journal of Intercultural Relations, Vol. 32, pp. 17-33.

*Straus, M.A., Hamby, S.L., Boney-McCoy, S. and Sugarman, D.A. (1996), "The revised Conflict Tactic Scale (CTS): developmental and psychometric data”, Journal of Family Issues, Vol. 17, pp. 283-316, available at: http://jfi.sagepub.com/

*Tenten, A., Sherman, M.D. and Han, X. (2009), "Violence between therapy-seeking veterans and their partners: prevalence and characteristics of nonviolent, mutually-violence, and one-sided couples", Journal of Interpersonal Violence, Vol. 24, pp. 111-27, available at: http://jiv.sagepub.com/

\section{Corresponding author}

Laura Stockdale can be contacted at: Istockdale@luc.edu

To purchase reprints of this article please e-mail: reprints@emeraldinsight.com Or visit our web site for further details: www.emeraldinsight.com/reprints 
Reproduced with permission of the copyright owner. Further reproduction prohibited without permission. 